\title{
Mathematical model of vacuum freeze-drying in the secondary drying
}

\author{
Hua Li, Lihua Li, Xingli Jiao, Xueli Qin
}

School of Chemical and Energy Engineering, Zhengzhou University, Zhengzhou 450001, China,

Email: lihua@zzu.edu.cn

School of Chemical and Energy Engineering, Zhengzhou University, Zhengzhou 450001, China,

Email: hua_iou@126.com

School of Chemical and Energy Engineering, Zhengzhou University, Zhengzhou 450001, China,

Email: jiaoxingli123@163.com

School of Chemical and Energy Engineering, Zhengzhou University, Zhengzhou 450001, China,

Email:943167120@qq.com

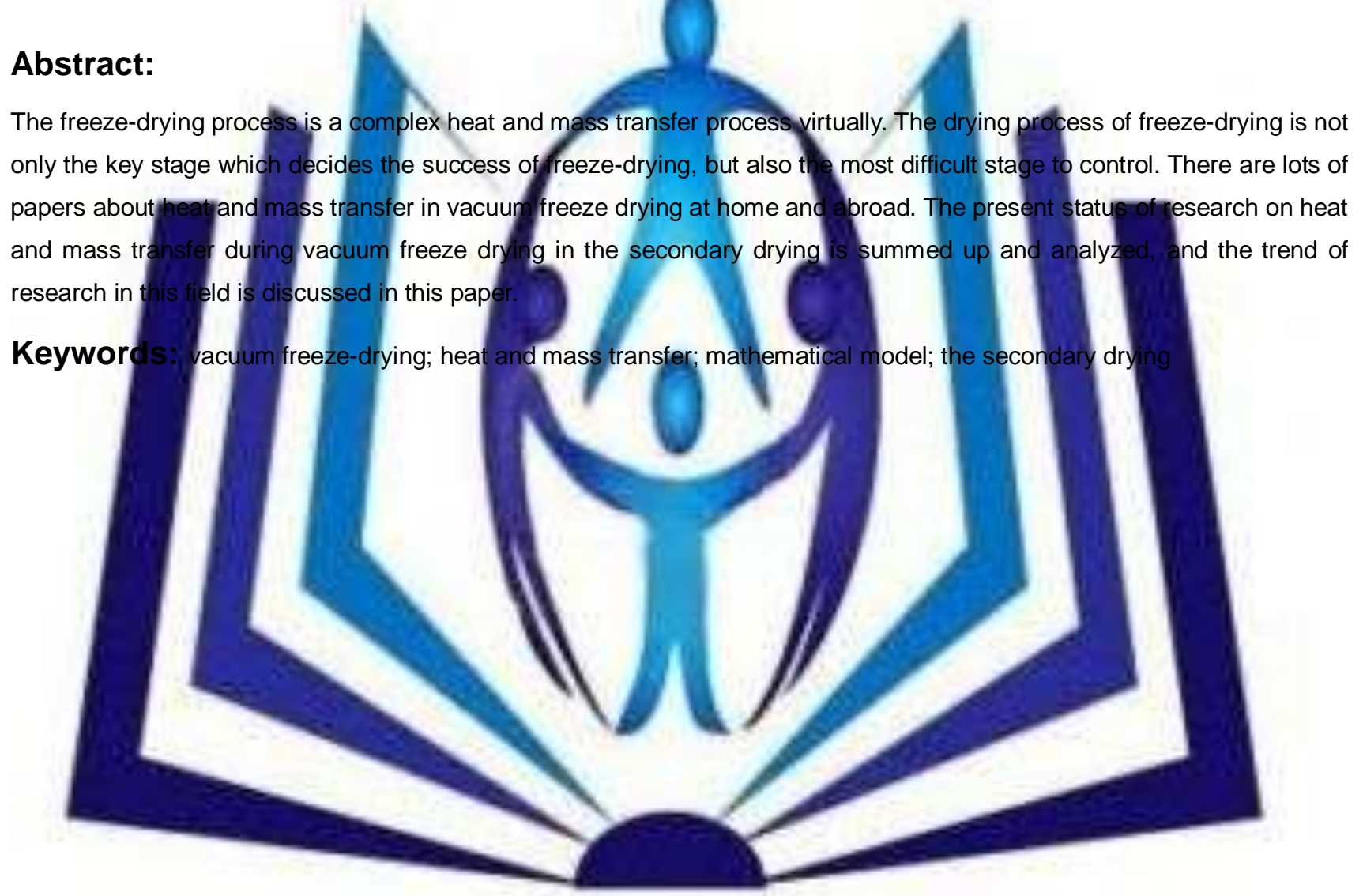

\section{Council for Innovative Research}

Peer Review Research Publishing System

Journal: Journal of Advances in Chemistry

Vol 3, No. 2

editor@cirworld.com

www.cirworld.com, member.cirworld.com

$192 \mid \mathrm{P}$ a g e 


\section{Introduction}

The secondary drying is the last stage of the freeze-drying process which is a desorption step where the residual moisture is reduced to a low level ensuring long-term product preservation at room temperature. At the condition of vacuum, materials which are heated to sublimation during primary drying are heated up again during the secondary drying. And the water taken away is mainly combined water in materials, and the energy is mainly used for desorption and sublimation of combined water. However, after primary drying, there is a little of frozen water in materials that is sublimated and taken away during the secondary drying process ${ }^{[1]}$. The secondary drying is usually carried out at high vacuum and moderate temperature ${ }^{[2]}$.

\section{Mathematical model of the secondary drying}

\subsection{The energy equation and mass equations of the secondary drying}

After the primary drying is finished, the process passes into the secondary drying and the temperature is higher. There is no frozen layer in the material at the moment, so the whole material can be taken into consideration uniformly.

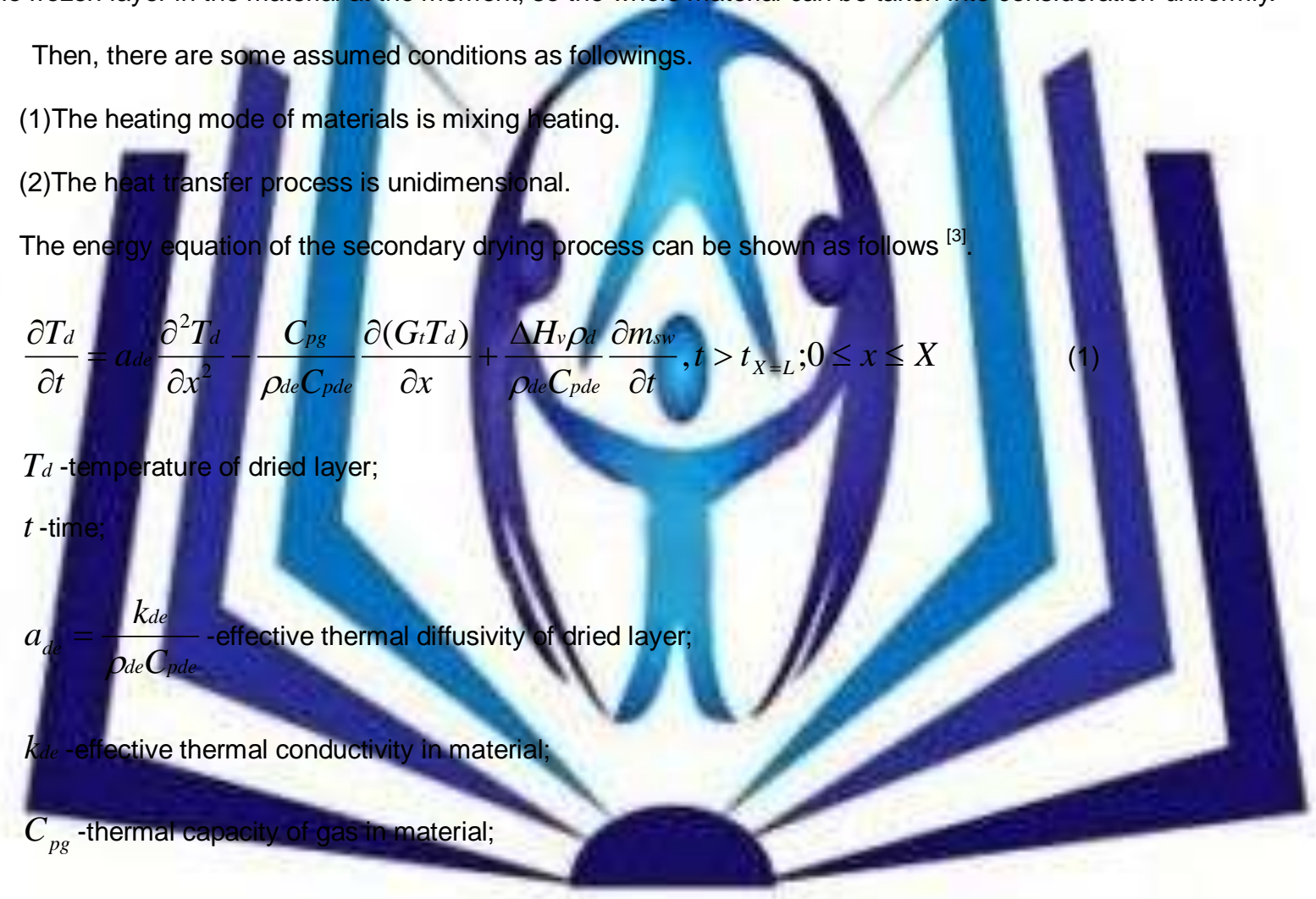

Pde -density of material;

$C_{p d e}$-effective thermal capacity of material;

$\Delta H v$-heat of desorption of combined water;

$G_{t}=G_{w}+G_{i}$-total flow rate of the gas extracted from the material;

$G_{w}$-flow rate of water vapor;

$G_{\text {in }}$-flow rate of non-condensable gas;

$\rho d$-density of dried layer during the secondary drying; 
$m_{s w}$-ratio of desorbed combined water.

In the equation above, the last term represents the desorption during the secondary drying, which not only can't be ignored, but also is the most important term. $m_{s w}$ means the ratio of solid combined water, while $m_{s w}^{*}$ means the ratio of solid combined water when the pressure of water vapor $p_{d w}$ is at equilibrium state. The principle that $m_{s w}$ varies over time can be shown: $\frac{\partial m_{s w}}{\partial t}=f_{s}\left(m_{\mathrm{sw}}^{*}-m_{s w}\right)$ or $\frac{\partial m_{s w}}{\partial t}=-f_{d} m_{s w}$. The $m_{s w}^{*}$ can be calculated approximately with the equation: $m_{s w}^{*}=\exp \left\{2.3\left[1.36-0.036\left(T-T^{0}\right)\right]\right\} / 100, \mathrm{~kg}_{w a t e r} / \mathrm{kg}_{d r y}{ }^{[4]} . T^{0}$ means the initial temperature. And $f_{s}$ and $f_{d}$ can be calculated by fitting experimental values and theoretical calculations.

The mass equation of water vapor of the secondary drying is:

$$
\frac{1}{R} \frac{\partial}{\partial t}\left(\frac{p_{d w}}{T_{d}}\right)=-\frac{1}{M_{w} \varepsilon} \frac{\partial G_{w}}{\partial x}, t>t_{X=L} ; 0 \leq x \leq X
$$

The mass equation of non-condensable gas of the secondary drying is:

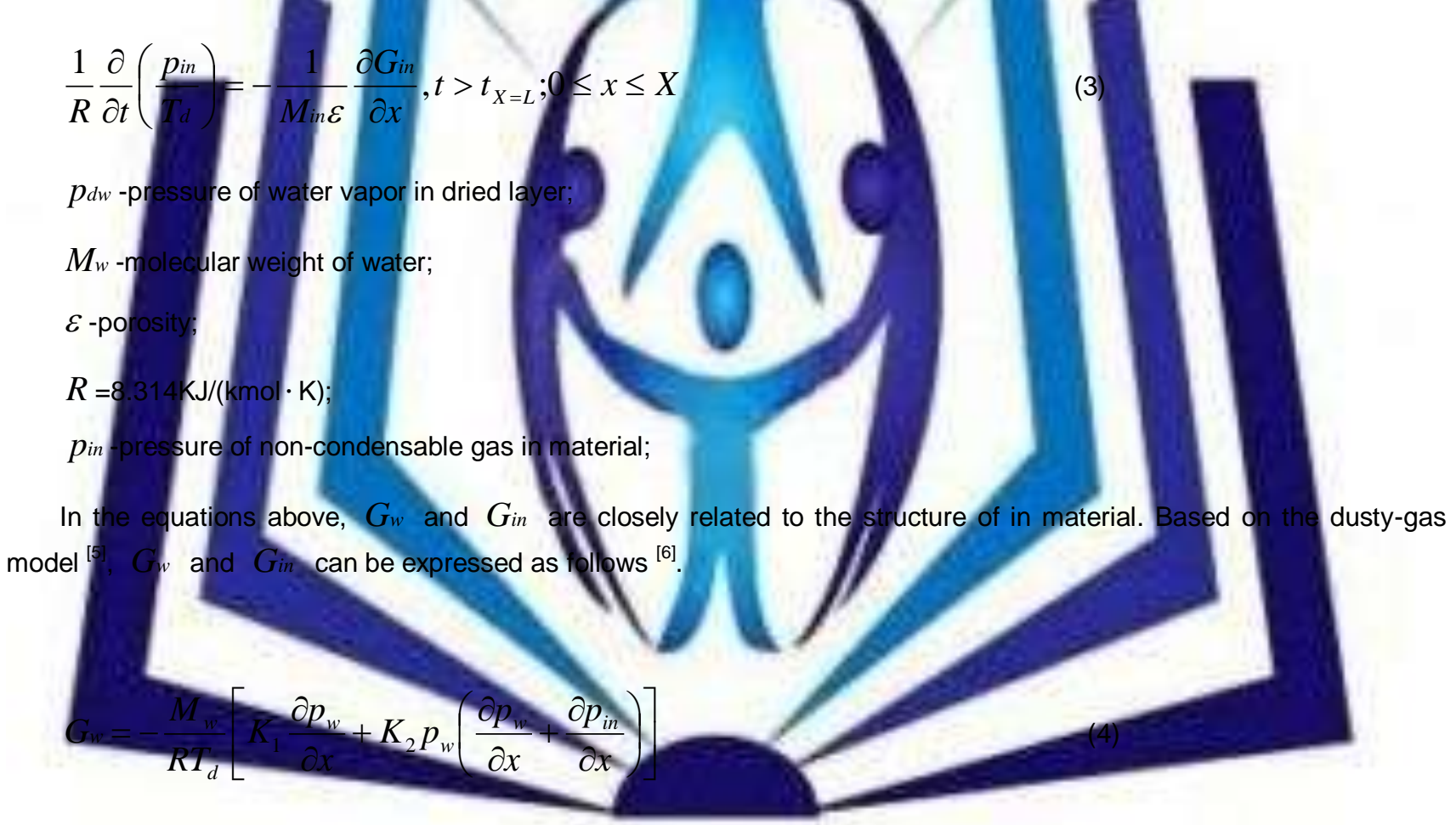

$$
G_{i n}=-\frac{M_{i n}}{R T_{d}}\left[K_{3} \frac{\partial p_{i n}}{\partial x}+K_{4} p_{i n}\left(\frac{\partial p_{w}}{\partial x}+\frac{\partial p_{i n}}{\partial x}\right)\right]
$$

So we can find the complex effects of structure and other factors by $\mathrm{K}_{1}, \mathrm{~K}_{2}, \mathrm{~K}_{3}$ and $\mathrm{K}_{4}{ }^{[7]}$. And the mass balance partial differential equations about $p_{w}$ and $p_{\text {in }}$ are shown as follows.

$$
\varepsilon \frac{\partial}{\partial t}\left(\frac{p_{w}}{T_{d}}\right)=\frac{\partial}{\partial x}\left\{\frac{1}{T_{d}}\left[K_{1} \frac{\partial p_{w}}{\partial x}+K_{2} p_{w}\left(\frac{\partial p_{w}}{\partial x}+\frac{\partial p_{i n}}{\partial x}\right)\right]\right\}, t>t_{X=L} ; 0 \leq x \leq L
$$


$\varepsilon \frac{\partial}{\partial t}\left(\frac{p_{i n}}{T_{d}}\right)=\frac{\partial}{\partial x}\left\{\frac{1}{T_{d}}\left[K_{3} \frac{\partial p_{i n}}{\partial x}+K_{4} p_{i n}\left(\frac{\partial p_{w}}{\partial x}+\frac{\partial p_{i n}}{\partial x}\right)\right]\right\}, t>t_{X=L} ; 0 \leq x \leq L$

\subsection{Simplification of energy equation and mass equation of the secondary drying}

In the secondary drying process, if diffusion is the only mass transfer way in porous dried layer, and the thermal physics of materials is constant, the equation (1) can be simplified as follows.

$$
\frac{\partial T_{d}}{\partial t}=a_{d e} \frac{\partial^{2} T_{d}}{\partial x^{2}}+\frac{\Delta H_{v} \rho_{d}}{\rho_{d e} C_{p d e}} \frac{\partial m_{s w}}{\partial t}, t>t_{X=L} ; 0 \leq x \leq X
$$

And if the ratio of mass of removed water vapor in materials and increased temperature is constant, the following equation is true ${ }^{[8]}$.

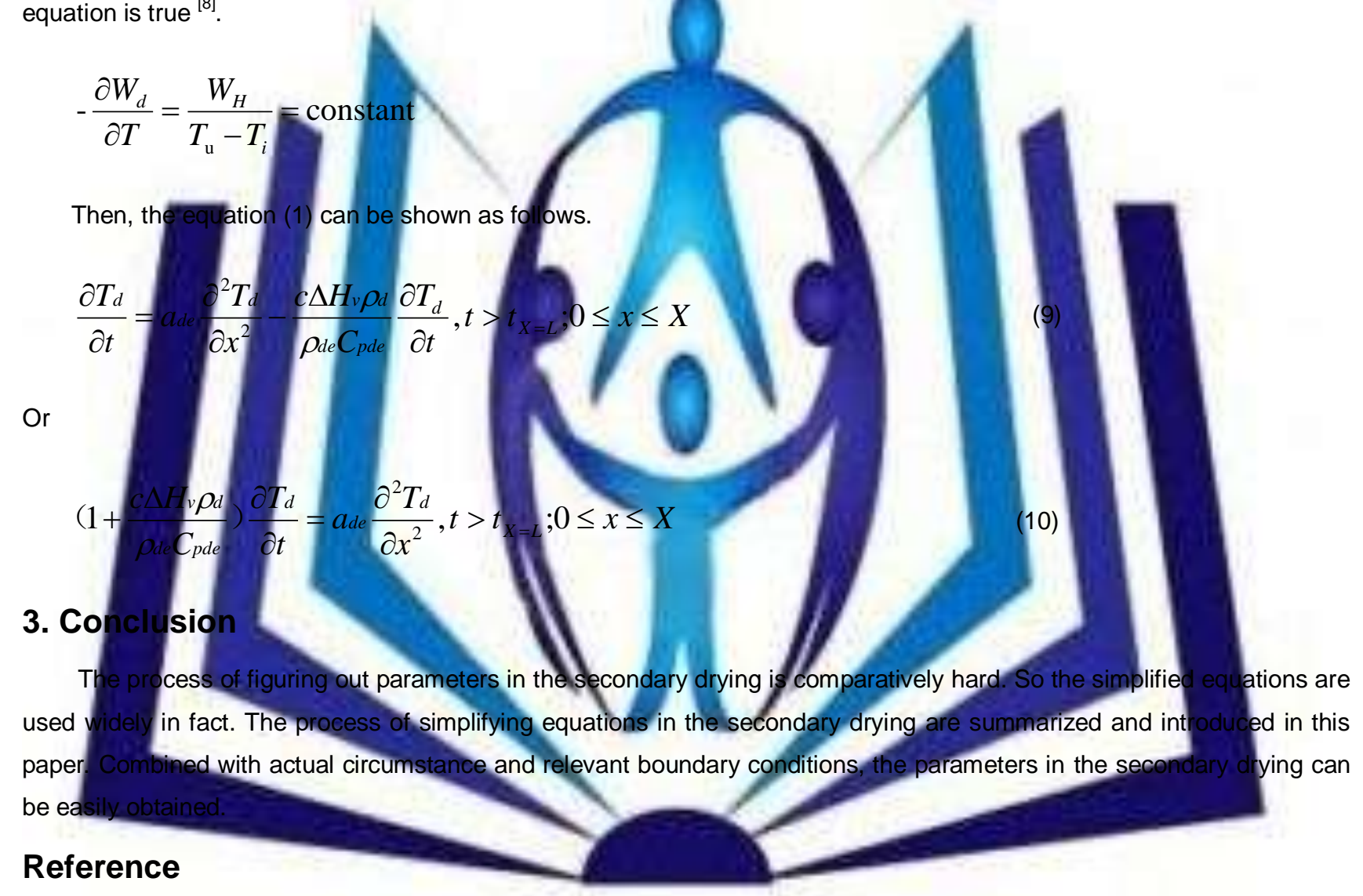

[1] Hua, Z. Z.; Liu, B. L.; Zuo, J. G. Freeze-Drying of Pharmaceutical and Food Products. Science Press, Beijing, 2006.

[2] Salvatore, A.; Velardi, A.; Barresi, A. Development of Simplified Models for the Freeze-Drying Process and Investigation of the Optimal Operating Conditions. Chemical Engineering Research and Design. 2008, 86(1): 9-22.

[3] Hua, Z. Z. A New Technology of Freeze Dying. Science Press, Beijing, 2005.

[4] Sadikoglu, H.; Liapis, A. I. Mathematical Modeling of the Prime and The secondary drying Stages of Bulk Solution Freeze Drying in Trays: Parameter Estimation and Model Discrimination by Comparison of Theoretical Results with Experimental Data. Drying Technology. 1997, 15: 791-810.

[5] Mason, E. A.; Malinauskas, A.P. Gas Transport in Porous Media: the Dusty-gas Model [M]. Amsterdam: Elsevier. 1983. 
[6] Bruttini, R., Rovero, G.; Baldi, G. Experimentation and Modeling of Pharmaceutic Lyophilization Using a Pilot Plant. The Chemical Engineering Journal. 1991, 45(3): 175-177.

[7] Millman, M. J.; Liapis, A. I.; Marchello, J. M. An Analysis of the Lyophilization Process Using a Sorption- sublimation Model and Various Operational Policies. AICHE Journal, 1985, 31(10): 1594-1604.

[8] Sheng, T. R.; Peck, R. E. Rates for Freeze Drying. AICHE Symp. Series. 1975, 73(163): 124-125.

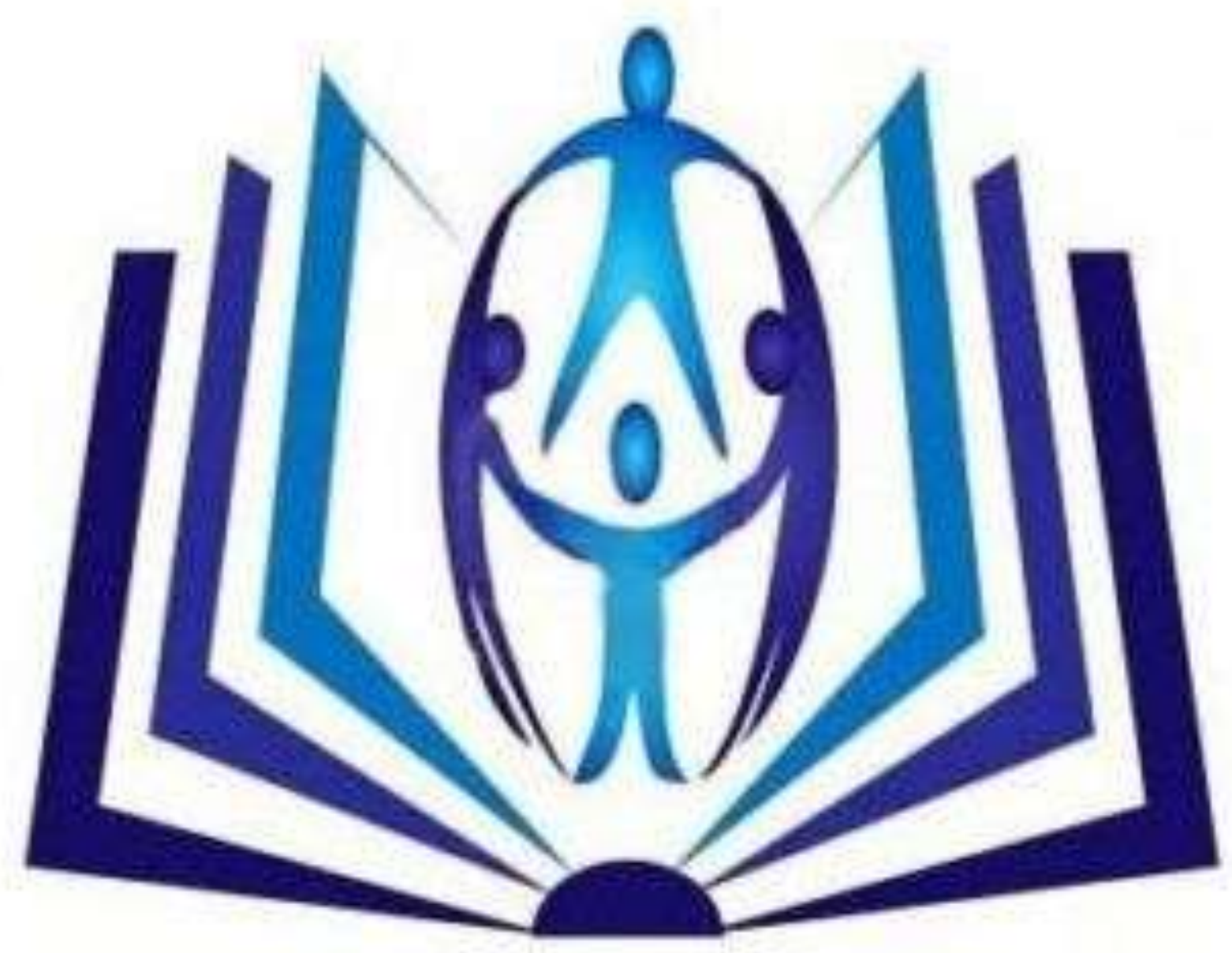

